\title{
New approaches to glycoconjugate synthesis
}

\author{
Richard R. Schmidt \\ Fakultät Chemie, Universität Konstanz, Postfach 5560 M 725 \\ D-78434 Konstanz, Germany
}

\begin{abstract}
Generally convergent strategies are employed in glyconjugate synthesis, hence the oligosaccharide moiety and the aglycon moiety are separately prepared and then linked to yield the target molecule; for glycopeptides linear synthesis strategies are more successful. - The importance of $\beta$-glycosidic linkages of glucosamine and galactosamine in glycoconjugates was reason for the development of new methods which are based on N,N-diacetyl, N-tetrachlorophthaloyl, and Ntrichloroethoxycarbonyl protection. - Another important goal in the construction of oligosaccharides is solid phase synthesis; the application of O-glycosyl trichloroacetimidates as donors, thiolinkers to the solid phase, and MALDI-MS for product analysis led to improvements in this regard. - Trichloroacetimidate-based glycosylation can be also applied to the synthesis of acid labile glycosyl phosphates and their lipid and nucleoside derivatives. Hydrolytically more stable glycophospholipids are GPI anchors; a general approach for ceramide-1-phosphate and phosphatidic acid derived GPI anchors is based on a versatile building block strategy.
\end{abstract}

\section{GLYCOCONJUGATE SYNTHESES - GENERAL STRATEGY}

Glycoconjugates consist of oligosaccharides which are glycosidically linked to lipids (diacylglycerol, ceramide, steroids, long chain fatty alcohols, etc.), to phospholipids (phosphatidylinositol $\rightarrow$ GPI anchors), to peptides ( $\mathrm{O}$ - and $\mathrm{N}$-linkage), and to a combination of all these compounds (for instance, in the GPI anchored proteins/glycoproteins) (ref. 1). Therefore, the synthesis of glycoconjugates consists of the oligosaccharide synthesis, the aglycon synthesis, and then their linkage to yield the target molecule. Commonly glycoconjugate synthesis follows this convergent strategy, hence the glycosidic linkage between the two moieties is performed at a very late stage. However, in some cases - starting from the oligosaccharide - the aglycon is constructed in a linear strategy because formation of the final glycosidic linkage is not compatible with the completed algycon moiety.

Simple glycolipids, as for instance calonyctin A and saponins which were recently synthesized by us (ref. 2,3) are successfully obtained in a convergent strategy; it is based on independent syntheses of the oligosaccharide portion and the lipid fragment and their linkage which is generally followed by protective group removal (often only O-acyl groups). The synthesis of the important glycosphingolipids (GSL) - including the structurally related gangliosides - follows a similar strategy; however, due to the low reactivity of the ceramide moiety, the oligosaccharide part is generally linked to azidosphingosine, which is independently prepared. Hence the last step consists of the attachment of the fatty acyl residue to the amino group of sphingosine which is released from the azido group in a reductive step (ref. 4). This "azidosphingosine glycosylation procedure", as introduced by us (ref. 5), has gained wide application. For the equally important glycopeptide synthesis a linear strategy has become typical (ref. 6), as shown in Scheme 1 (ref. 7), because direct glycosylation of peptides has not yet been very successful. Hence, firstly the oligosaccharide moiety is synthesized which is then attached to the required amino acid (for O-glycosides generally $\alpha$-linked serine or threonine and for $\mathrm{N}$-glycosides, generally $\beta$-linked asparagine). With this building block in hand the ensuing glycopeptide synthesis is carried out following standard peptide synthesis procedures which often employ solid phase techniques.

\section{N-ACETYLGLUCOSAMINE AND -GALACTOSAMINE IN $\beta$-GLYCOSIDIC LINKAGES}

Obviously, oligosaccharide synthesis is regarded as an experimentally quite demanding problem in itself, which is solved in an independent approach applying appropriate methodologies for the regio- and diastereoselective linkage of sugar residues. Important target molecules have been in the last years sialyl Lewis X (sLex) (ref. 8-10) and GM1 (ref. 4) (Scheme 2). The retrosynthetic analyses exhibit the 
Scheme 1

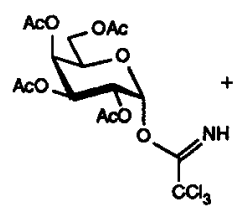

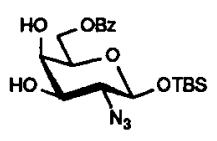

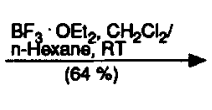
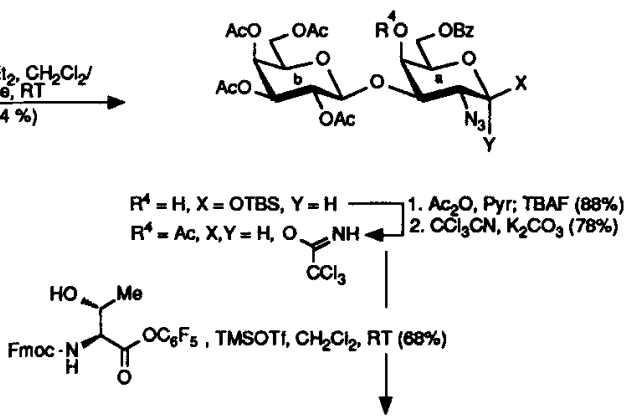

$\underbrace{A C O}_{O A C}$

Solid Phase Peptide Synthesis 2. $\mathrm{CH}_{3} \mathrm{COSH}, \mathrm{Pyr}$

$\mathrm{CF}_{3} \mathrm{CO}_{2} \mathrm{HH}_{2} \mathrm{O}$

AC-Lou-Glu-Thr-Ser-Thr-Gly-NH

$(58 \%)$

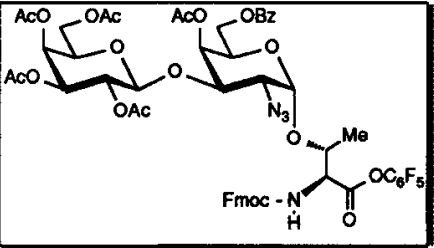

$\underset{(82 \%)}{\mathrm{NaOMe}, \mathrm{MeOH}}$

Galß(1-3)GaINACOU(1-O)

AC-Leu-Glu-Thr-Ser-Thr-Gly-NH

Scheme 2
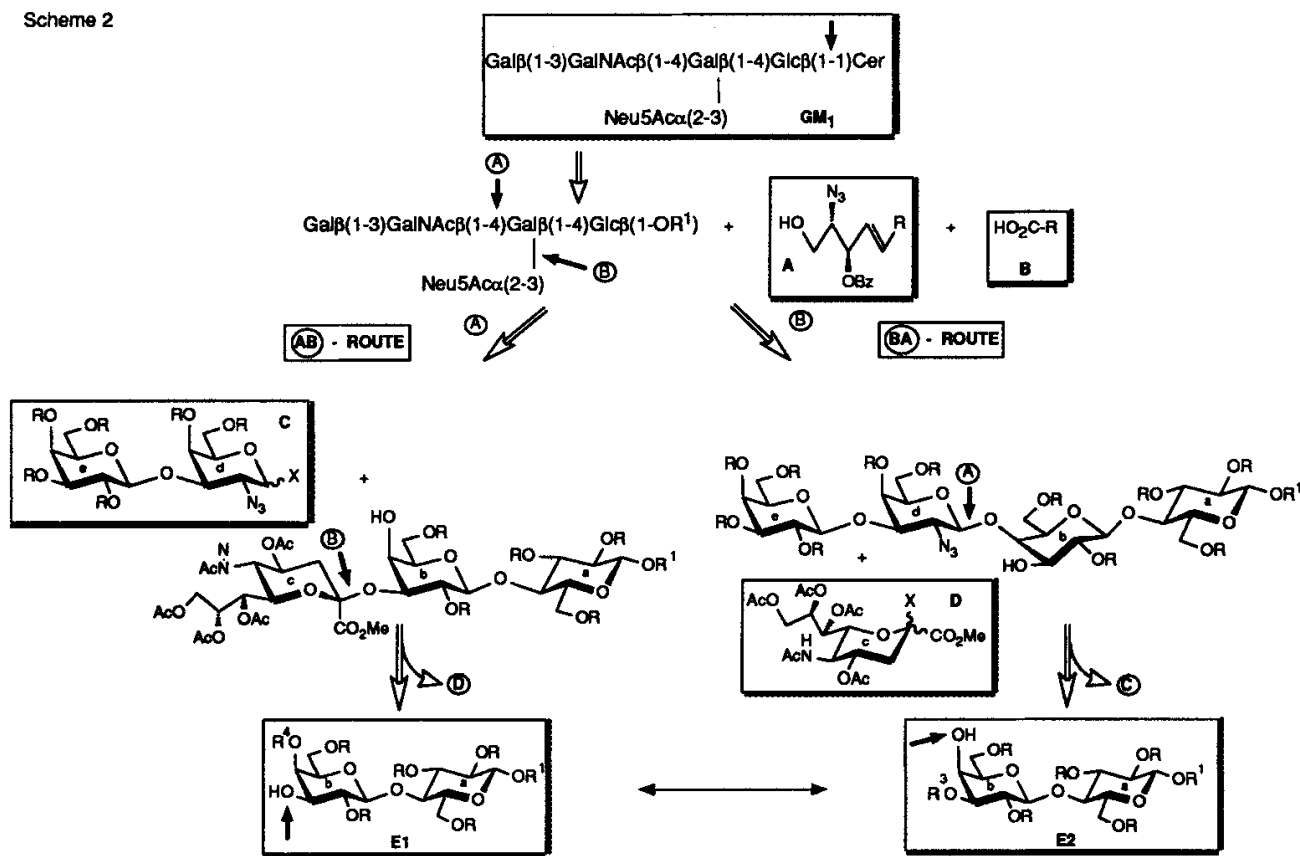

presence of $\mathrm{N}$-acetylglucosamine (GlcNAc) and of $\mathrm{N}$-acetyl-galactosamine (GalNAc) in decisive $\beta$ glycosidic linkages which ligate various building blocks. Because direct glycosylation with activated Nacetyl derivatives of GlcNAc and GalNAc procedes via relatively unreactive oxazolinium intermediates, we have been engaged in the development of glycosylation methods overcoming this disadvantage.

In the beginning of the investigations, our attention was focussed on the corresponding 2-azido-2-deoxy derivatives (Scheme 2) which with the help of trichloroacetimidate activation resulted in very efficient glycosyl donors for the synthesis of sLex and GM1 and various structurally related compounds (ref. $4,7,10$, and 11). However, the difficulties in the synthesis of the azido derivatives from the corresponding glycals (lack of diastereospecificity in the azide introduction, low yields, etc.) were 
Scheme 3

TCP-PROTECTION

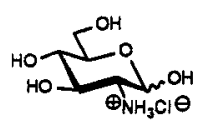

NaOMe, MeOH, TCPO; $\mathrm{Ac}_{2} \mathrm{O}, \mathrm{Pyr}(\mathrm{qu})$

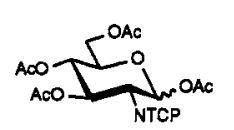

ACTIVATION

TCP

\begin{tabular}{|l}
\hline TCP-GROUP REMOVAL AND N-ACETYLATION \\
\hline (9) ${ }^{\mathrm{a}} \mathrm{CH}_{2} \mathrm{CH}_{2}(4.5 \mathrm{eq}), \mathrm{ETOH}, 60^{\circ} \mathrm{C}, 3.5 \mathrm{~h}$; \\
\\
\end{tabular}

a Braser-Reid, al, (1995)

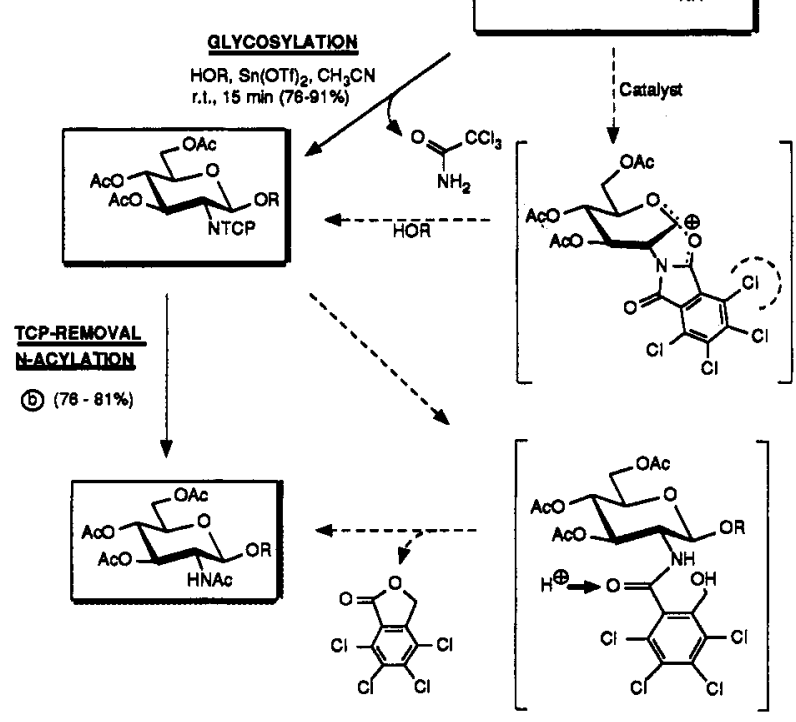

Scheme 4
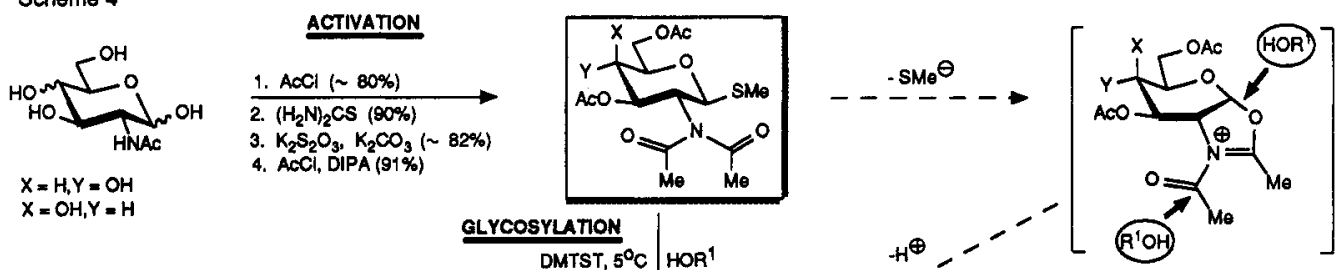

$X=O H, Y=H$
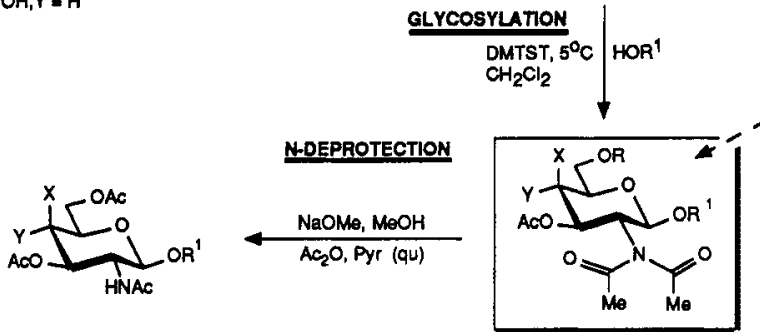

BYPAODUCTS

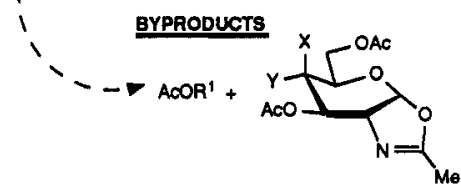

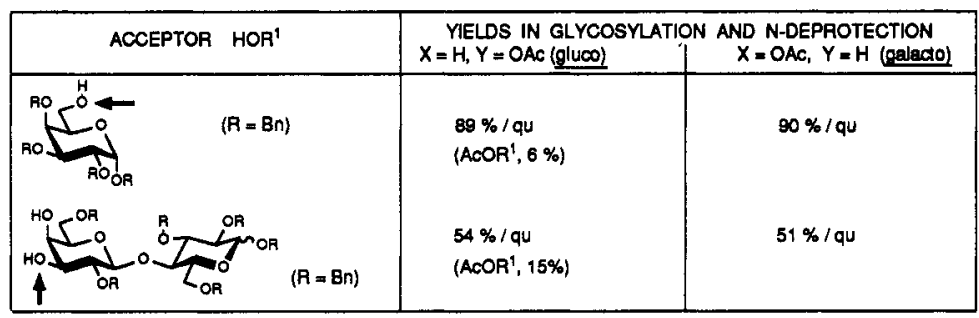

reason to look for more efficient and simple approaches. $\alpha$-Specific thermal inverse-type hetero-DielsAlder reaction of azodicarboxylates to glycals was our first attempt, thus leading to concomitant addition of an amino group equivalent and to activation of the anomeric carbon when trichloroethyl azodicarboxylate was used (ref. 12). However, contrary to other reports (ref. 13), we could not confirm for these compounds high glycosylation potential which was sufficient for complex oligosaccharide synthesis. Therefore, we tried to improve the properties of the N-phthalimido protected glycosyl donors by resorting to the N-tetrachlorophthalimido (TCP) analogue; indeed, this led to very high glycosyl 
donor properties and convenient cleavage of the TCP group was gained - as exhibited in Scheme 3 (ref. 14). Even as more convenient glycosyl donors were regarded $\mathrm{N}, \mathrm{N}$-diacetyl derivatives of glucosamine and galactosamine, which - as demonstrated in Scheme 4 - exhibit good glycosyl donor properties and mos simple deprotection (ref. 15). Hoewer, their base and acid lability led for less reactive glycosyl acceptors to competing acetyl transfer (to the acceptor); therefore, the application of these donors is most successful for reactive acceptors. An ideal combination of the properties of the N-TCP and the $\mathrm{N}, \mathrm{N}$-diacetyl compounds seems to exhibit the $\mathrm{N}$-trichloroethoxycarbonyl (N-Teoc) group (ref. 16). The corresponding trichloroacetimidates can be readily obtained, they exhibit high glycosyl donor properties, and transformation of the products into the $\mathrm{N}$-acetyl functionality can be performed by a simple one pot procedure - as demonstrated in Scheme 5 for the reaction of various acceptors.
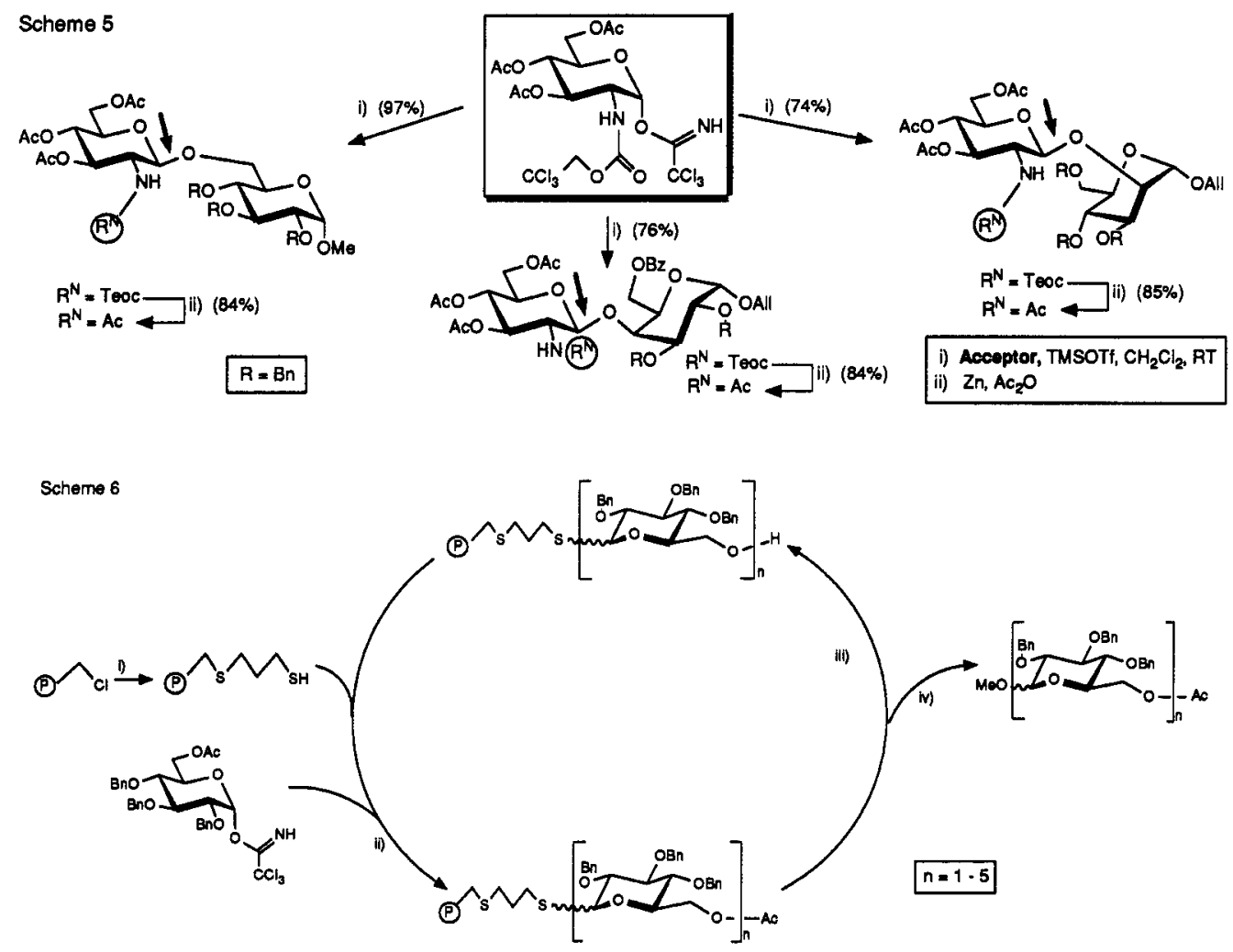

$$
\begin{aligned}
& \text { Propanedithiol (10 eq), DBU (2 eq), Tol, RT }(-0.6 \mathrm{mmol} / \mathrm{g}) \\
& \text { ii) Trichioroacetimidate ( } 3 \text { eq). TMSOTf }(0.2 \mathrm{eq}), \mathrm{CH}_{2} \mathrm{Cl}_{2}, \mathrm{RT}, 2 \mathrm{~h}(>95 \%, \alpha: \beta \sim 1: 1) \\
& \text { iii) } \mathrm{NaOMe}, \mathrm{MeOH}\left(0.5 \mathrm{M} / \mathrm{CH}_{2} \mathrm{Cl} / 2 \text { (1:9), RT, } 2 \mathrm{~h} \text {; } 15-\mathrm{crown}-5 \text { (2 eq), } \mathrm{CH}_{2} \mathrm{Cl}_{2} / \mathrm{MeOH}, 20: 1\right. \text { (qu) } \\
& \text { iv) DMTSB (2 өq), EtNiPr2 (2 eq). } \mathrm{CH}_{2} \mathrm{Cl}_{2} / \mathrm{MoOH}, 9: 1 \text { (qu) }
\end{aligned}
$$

\section{NEW APPROACH TO SOLID PHASE OLIGOSACCHARIDE SYNTHESIS}

Another means to ease oligosaccharide synthesis consists in the use of a solid phase support. Important aspects which have to be considered in this endeavour are (i) attachment of a suitable linker to the solid phase material (exhibiting orthogonal stability to the glycosylation procedure) and then attachment of the first sugar residue to the linker in a standard glycosylation procedure, (ii) rapid analysis of all solid phase reactions, and (iii) repetitive regio- and diastereoselective glycosylation, cleavage from the linker, and deprotection each in very high yields. We have recently employed thiolinkers together with Oglycosyl trichloroacetimidates as glycosyl donors; analysis of the glycosylation was based on MALDIMS analysis (Scheme 6) (ref. 17). Cleavage from the linker was performed via thioglycoside activation in the presence of methanol, thus affording the methyl saccharide in high yield, which was then deprotected by standard procedures; the glycosylation reaction was carried out at room temperature, thus a 1:1 mixture of the anomers could be obtained exhibiting the potential of this method also in combinatorial syntheses (ref. 17). With the help of neighboring group participation also anomer selective reaction control is possible, thus leading to structurally defined reaction products (ref. 18). Yet, 
quite a few problems have to be solved until this approach will be competitive with or even superior to solution synthesis of complex oligosaccharides.
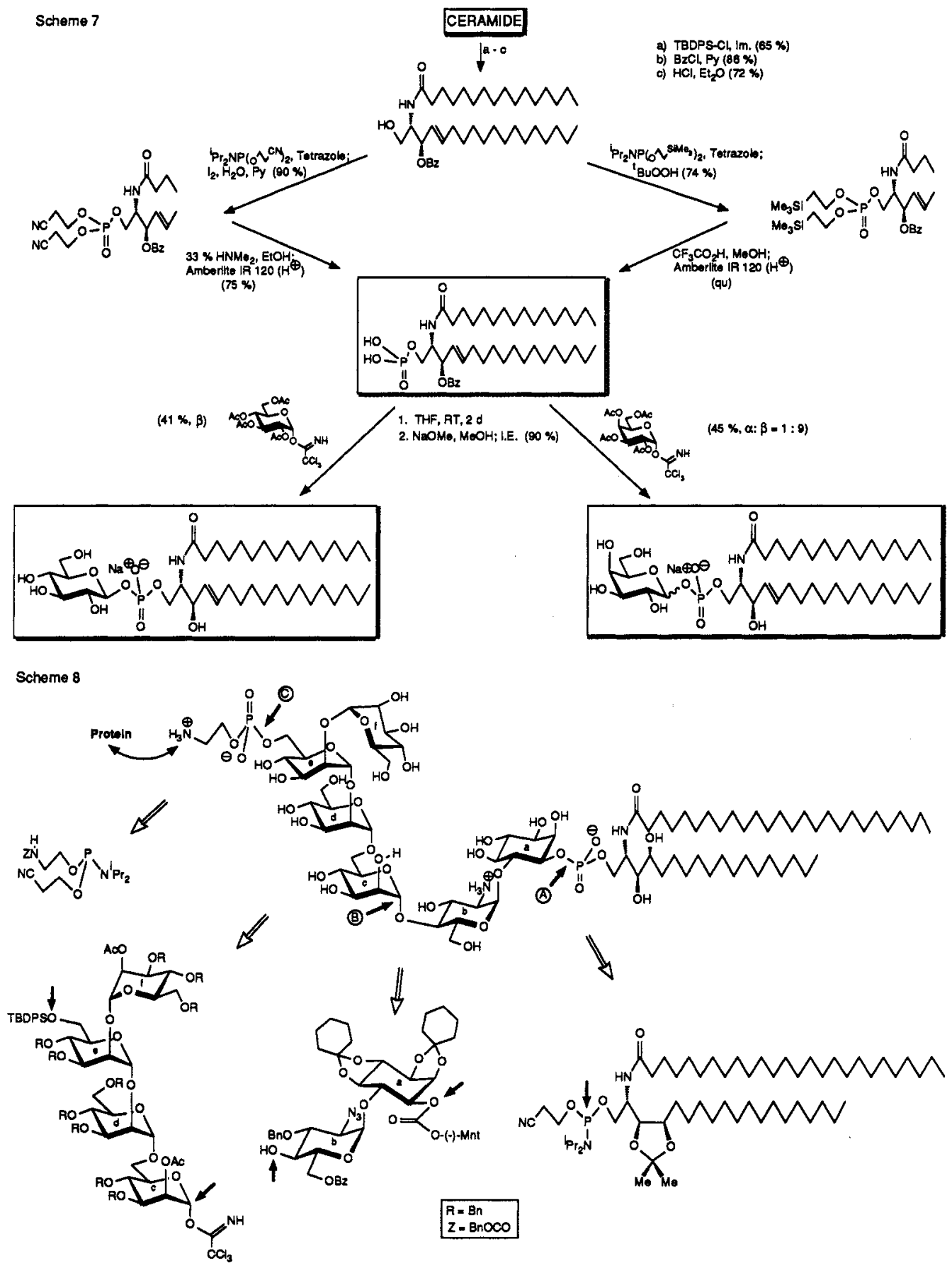

\section{A VERSATILE GPI ANCHOR SYNTHESIS}

Glycosylation of alcohols (including sugar hydroxy groups) follows on acid catalyzed trichloroacetimidate/- or phosphite/-alcohol exchange reaction releasing trichloroacetiamide or phosphonate (ref. 10,11, and 19). Direct exchange of these leaving groups at the anomeric position by 
phosphorous acid esters (for instance, phospholipids, nucleoside-monophosphoric acids, etc.) leads directly to glycosyl phosphates (ref. 11,20) which constitute interesting glycoconjugates used by nature. An example of these reactions is shown in Scheme 7, leading to an interesting class of phospholipids (ref. 21), which could be membrane constituents; however, due to the lability of the glycosidic bond, nature did not use this type of compounds for this purpose. To overcome the stability problem, a pseudosugar, namely inositol, was employed instead. Thus, the glycosylphosphatidyl inositol (GPI) compounds are generated which possess great importance in anchoring proteins and glycoproteins in membranes (ref. 22). Various structural types have been identified and the first synthetic approaches have been reported (ref. 23). We have concentrated on the total synthesis of a ceramide-1-phosphate residue containing GPI anchor which appears in Saccharomyces cerevisiae (ref. 24). The strategy of this approach - as exhibited in Scheme 8 - is a basis for extensive syntheses in this highly demanding field. For instance, phosphatidyl derivatives with photo, fluorescence, and radio labels, required for biological studies, have been recently successfully obtained by us via methodology (ref. 25).

\section{ACKNOWLEDGEMENTS}

It is a great pleasusre to acknowledge the contributions of the very capable collaborators, who developed the methodologies described in this paper. They are individually mentioned in the references.

This work was supported by the Deutsche Forschungsgemeinschaft and the Fonds der Chemischen Industrie.

\section{REFERENCES}

1. R.R. Schmidt, Pure Appl. Chem. 61, 1257-1270 (1989); and references therein.

2. Z.-H. Jiang and R.R. Schmidt. Angew. Chem. 107, 2730-2734 (1995); Angew.üs Chem. Int. Ed. Engl. 34, 2520-2524 (1995); Liebigs Ann. Chem. 645-651 (1994).

3. Z.-H. Jiang, X.-B. Han, and R.R. Schmidt. Liebigs Ann. Chem. 1179-1184 (1993); and references therein.

4. U. Greilich, R. Brescello, K.-H. Jung, and R.R. Schmidt. Liebigs Ann. 663-672 (1996); and references therein.

5. R.R. Schmidt and P. Zimmermann. Tetrahedron Lett. 27, $481-484$ (1986); Angew. Che. 98, $722-723$ (1986); Angew. Chem. Int. Ed. Engl. 25, 725-726 (1986); P. Zimmermann, R. Bommer, T. Bär, and R.R. Schmidt. J. Carbohydr. Chem. 7, 435-452 (1988).

6. H.G. Garg, K. von dem Bruch, and H. Kunz. Adv. Carbohydr. Chem. Biochem. 50, 277-310 (1994); H. Paulsen, Angew. Chem. 102, 851-867 (1990); Angew. Chem. Int. Ed. Engl. 29, 823-838 (1990): K.J. Jensen, M. Meldal, and K. Bock. J. Chem. Soc., Perkin Trans. 1, 2119-2129 (1993); and references therein.

7. J. Rademann and R.R. Schmidt. Carbohydr. Res. 269, 217-225 (1995).

8. M. Iida, A. Endy, S. Fujita, M. Numata, Y. Matsuzaki, M. Sugimoto, S. Nunomura, and T. Ogawa. Carbohydr. Res. 270, C15-C19 (1995).

9. A. Kameyama, T. Eharu, Y. Yamada, H. Ishida, M. Kiso, and A. Hasegawa. J. Carbohydr. Chem. 14, $507-523$ (1995).

10. R.R. Schmidt. In Synthetic Oligosaccharides - Indispensible Probes for Life Sciences (P. Kovac, ed.) pp. 276-296. ACS Symposium Series 560, Washington DC (1994); G. Hummel and R.R. Schmidt. Tetrahedron Lett., submitted.

11. R.R. Schmidt. Angew. Chem. 98, 213-236 (1986); Angew. Chem. Int. Ed. Engl. 25, 212-235 (1986).

12. A. Toepfer and R.R. Schmidt. Carbohydr.Res. 243, 159-164 (1993).

13. Y. Leblanc, B.J. Fitzsimmonis, J.P. Springer, and J. Rokach. J. Am. Chem. Soc. 111, 2995-3000 (1989); R. Grondin, Y. Leblanc, and K. Hoogsten. Tetrahedron Lett. 32, 5021-5024 (1991); and references therein.

14. J.-C. Castro-Palomino and R.R. Schmidt. Tetrahedron Lett. 36, 5343-5346 (1995).

15. J.-C. Castro-Palomino and R.R. Schmidt. Tetrahedron Lett. 36, 6871-6874 (1995).

16. W. Dullenkopf, J.-C. Castro-Palomino, L. Manzoni, and R.R. Schmidt. Carbohydr. Res., in print.

17. J. Rademann and R.R. Schmidt. Tetrahedron Lett. 37, 3989-3990 (1996).

18. J. Rademann. Investigations for the Dissertation.

19. T.J. Martin, R. Brescello, A. Toepfer, and R.R. Schmidt. Glycoconjugate J. 10, 16-25 (1993); and references therein.

20. T.J. Martin and R.R. Schmidt. Tetrahedron Lett. 34, 1765-1768 (1993).

21. T.J. Martin, G. Dufner, B. Kratzer, and R.R. Schmidt. Glycoconjugate J. 13 (1996), in print.

22. M.A.J. Ferguson and A.F. Williams. Annu. Rev. Biochem. 57, 285-320 (1988); and references therein.

23. C. Murakata and T. Ogawa. Carbohydr. Res. 234, 75-91 (1992).

24. T.G. Mayer, B. Kratzer, and R.R. Schmidt. Angew. Chem. 106, 2289-2293 (1994); Angew. Chem. Int. Ed. Engl. 33, 2177-2181 (1994).

25. T.G. Mayer, Dissertation, Univ. Konstanz, submitted. 